was hardly necessary. It was important that the candidate should possess normal reaction time (19/100 of a second).

There were aviators with defective vision who flew well, despite their disability, but Surgeon Anderson knew of many who had come to grief. "The pupil with defective vision who attempts to learn flying will probably crash." This statement, however, was qualified in the case of a pupil who had been an observer for some time, inasmuch as he would probably have learned by experience to modify his imperfect visual judgments. Anderson related the case of two pupils, each with imperfect sight, one corrected with glasses and the other not. Both learned to fly without trouble, and became good pilots, but then each had over 100 hours to his credit as an aerial observer.

In the discussion, Fleet-Surgeon R. C. Munday, R.N., spoke of the necessity of grading standards of fitness in accordance with the various flying duties, particularly the standards of sight. Questions of colour vision and the heterophoria were of vital importance. Surgeon-General Sir W. H. Norman, Director-General of the Navy Medical Service, laid stress on the importance of vision and good colour vision. Mr. E. Clarke expressed the view that every candidate's sight should be tested under a cycloplegic. Captain H. D. Briggs, R.N., thought that those with doubtful sight should fly alone, as they had no right to involve others in a risk which they took themselves. Sir James Galloway asked for some standardized method for the examination of colour vision. Mr. L. Vernon Cargill agreed as to the importance of heterophoria as a cause of accidents. Colour vision should be tested with the EdridgeGreen lamp. Stereoscopic vision and a perfect visual field in each eye were very necessary.

\title{
American College of Surgeons
}

Revised requirements for admission to the Fellowship of the American College of Surgeons, which have grown out of the experience gained by the College during the past four years, have recently been issued. Among important changes are those which aftect ophthalmologists who are candidates for the distinction. The new scheme as regards them will be worked out in co-operation with the American Board for Ophthalmic Examinations, which for the time being will be the same body as the Ophthalmic Credentials Committee of the College, the members of which are: Edward Jackson (Denver), Frank C. Todd (Minneapolis), William H.Wilder (Chicago), Edward C. Ellett (Memphis), Walter B. Lancaster (Boston), Hiram Woods (Baltimore), Myles Standish (Boston), and John E. Weeks (New York). In addition to the general requirements for admission to the Fellowship (except in regard to examinations in surgery to which ordinary candidates are subjected), 
the requirements in ophthalmology consist of : first, case-records ; second, written examination; and third, clinical, laboratory, and oral examinations. The written examination will test the candidate's knowledge of the underlying principles or science of ophthalmology, including anatomy, embryology, physiology, physiological optics, pathology, and relations of the eye to other organs and diseases of the body. Candidates in ophthalmology must submit twenty-five complete case-records, of which ten should be of ocular diseases and defects of varied character, including errors of refraction or muscle balance. The reports should show the reasons for diagnosis and for any operations, the technique of which should be described. The oral examination will include: (1) the external examination of the eye; (2) ophthalmoscopy; (3) estimation of errors of refraction; (4) testing of the ocular movements and of the fields of vision; (5) relations of ocular conditions to diseases of other parts of the body and their treatment; and (6) laboratory examination in histology, pathology, and bacteriology.

.The American College of Surgeons aims high both as regards the scientific standard and the personal character and record of the candidate. A qualification such as it provides should do much to elevate the practice of surgery and of the surgical specialities, of which ophthalmology is one. Moreover, it makes for the standardization of surgery, in itself no small gain.

\section{A Register of the Blind}

The Advisory Committee appointed by the President of the Local Government Board to assist him in matters concerning the care and supervision or the blind were confronted at the beginning of their labours by the lack of accurate statistical information as to the number and condition of the blind in England and Wales. The matter was at once referred to a sub-committee, and as a result of their enquiries and report efforts are now being made to compile a complete register of all persons who fall under the definition adopted by the Local Government Board, "too blind to perform work for which eyesight is essential."

This register will contain not merely names and addresses, but also particulars of each blind person, which will enable the authorities to form an opinion as to the best means of rendering assistance, by educating, occupational training, pensioning, etc.

The Local Government Board have now issued forms designed to obtain the desired information, and containing a series of questions to be answered on behalf of the blind. It is hoped that all Boards of Guardians, District Nursing Associations, and societies and institutions ministering to the blind, will assist in making the 